\title{
Interaction between nutrition and Eimeria acervulina infection in broiler chickens: diet compositions that improve fat digestion during Eimeria acervulina infection
}

\author{
BY C. ADAMS, H. A. VAHL AND A. VELDMAN* \\ CLO-Institute for Animal Nutrition 'De Schothorst', PO Box 533, 8200 AM Lelystad, \\ The Netherlands
}

(Received 4 January 1994-Revised 27 March 1995-Accepted 19 September 1995)

\begin{abstract}
Previously an experimental infection model was developed in which broiler chickens were inoculated with sporulated Eimeria acervulina oocysts at an age of $18 \mathrm{~d}$. The infection resulted in adverse performance results and reduced nutrient digestion. In two new experiments with the infection model effects of diet adjustments on fat digestion were investigated. In the first experiment addition of $0.4 \mathrm{~g}$ cholic acid $/ \mathrm{kg}$ to a diet rich in animal fat resulted in increased fat digestion during the infection. In the second experiment replacing animal fat by coconut oil resulted in improved fat digestion during the coccidiosis infection. However, replacement of animal fat by soyabean oil did not improve fat digestion.
\end{abstract}

Poultry: Coccidiosis: Fat digestion

In a previous paper (Adams et al. 1996) an infection model was introduced in which chickens were inoculated with sporulated Eimeria acervulina oocysts. As Eimeria acervulina affects a specific region of the intestine, this infectious disease can be used as a model to study nutrition-infection relationships in order to adjust diet compositions during the acute and recovery phases of enteral infections.

The aim of the present study was to use the infection model to test the effects of diet adjustment on fat digestion. In one experiment cholic acid was added to a diet in order to support bile function. Reduced bile excretion might be the reason for reduced fat digestion during coccidiosis. Krogdahl (1985) has suggested that bile salt supplementation might improve fat digestion when inadequate amounts of bile salts are secreted.

In the second experiment animal fat was replaced by coconut oil, which is relatively high in medium-chain triacylglycerols (MCT). MCT have certain advantages over long-chain triacylglycerols (LCT) which can be beneficial during intestinal disease (Bach \& Babayan, 1982). Also in Expt 2 animal fat was replaced by soyabean oil which has a high percentage of unsaturated fatty acids. Uptake of unsaturated fatty acids into micelles is facilitated in comparison with uptake of saturated fatty acids.

\section{MATERIALS AND METHODS \\ Animals and diet}

Female, Ross broiler chickens were obtained as 1-d old birds from a commercial hatchery. Chickens were kept in groups on electrically heated wire-floored batteries under constant lighting. Unmedicated feed and water were available ad libitum. All diets were formulated to meet or exceed the nutritional requirements of broilers as given by the National Research Council (1984). The composition of the diets is described in Table 1. Fatty acid patterns of

* For reprints. 
Table 1. Composition of experimental diets $(\mathrm{g} / \mathrm{kg})$

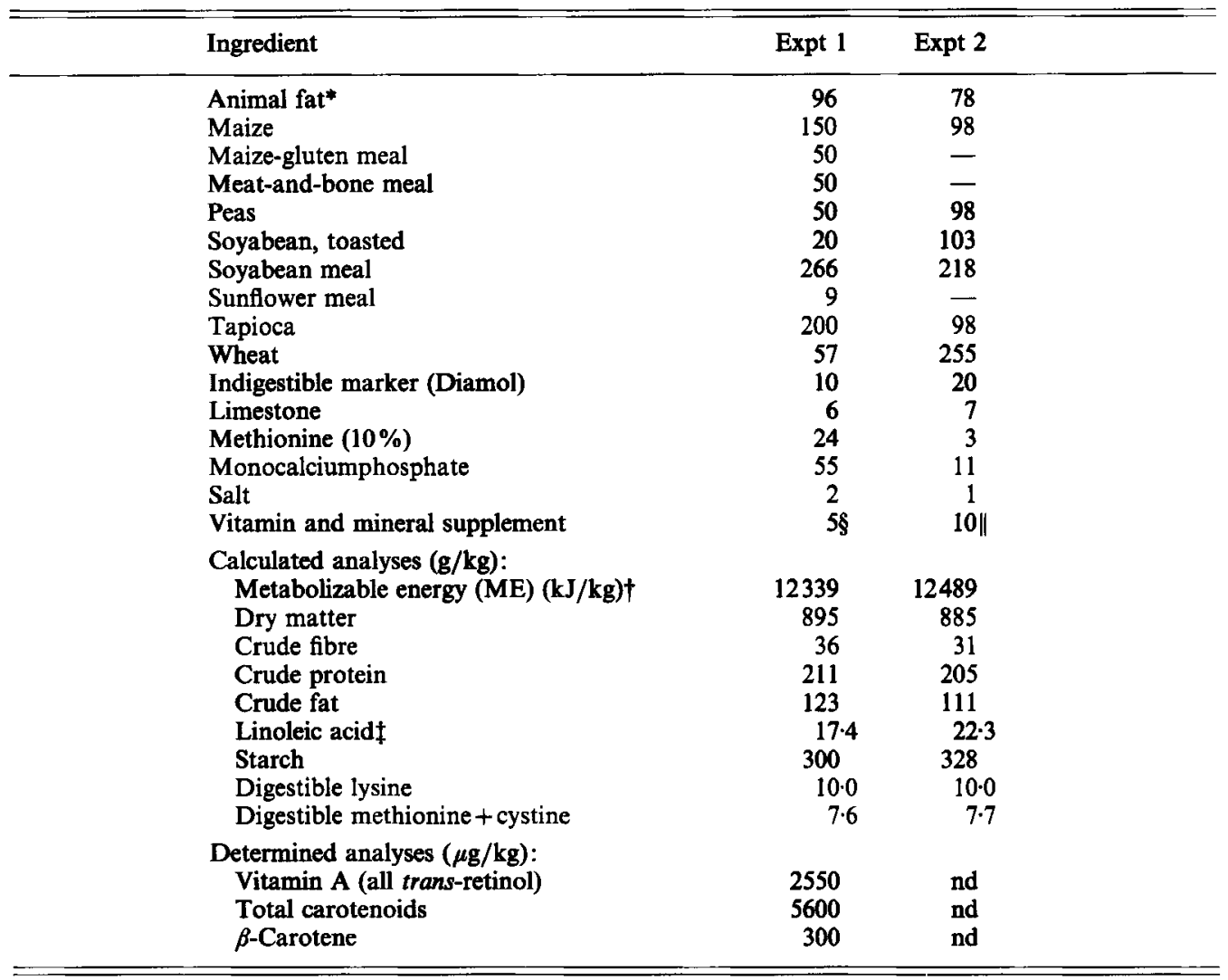

nd, not determined.

* In Expt 2 the fat was animal fat, coconut oil or soyabean oil.

$\dagger$ When coconut oil and soyabean oil were used ME values were 12560 and $12740 \mathrm{~kJ} / \mathrm{kg}$

\$ When coconut oil and soyabean oil were used linoleic acid concentrations were 16.7 and $55.3 \mathrm{~g} / \mathrm{kg}$ respectively in Expt 2.

$\S$ Vitamin and mineral supplement provided $(\mathrm{mg} / \mathrm{kg}$ diet): retinol 3, cholecalciferol 0.05 . $\alpha$-tocopherol 20 , riboflavin 4, niacin 31. D-pantothenic acid 8, choline 256 , cyanocobalamin $0-015$, biotin 0.025 , menadione $3 \cdot 3$, Cu 12.5, Fe 40, Mn 62.4, Zn 45, I 0.9, Se 0.1, Mo 0-12, zinc bacitracin 19, Natuphos $200 \mathrm{U} / \mathrm{kg}$.

\|| Vitamin and mineral supplement provided (mg/ $\mathrm{kg}$ diet): retinol 3, cholecalciferol $0.05, \alpha$-tocopherol 25 , riboflavin 4 , niacin 30 , D-pantothenic acid 7 , pyridoxine 1 , choline 220 , pteroylmonoglutamic acid 0.5 , cyanocobalamin 0.015 , biotin 0.025, menadione 1.3, Ca 1700, $\mathrm{Na} 800, \mathrm{Cl} 1250, \mathrm{Cu} 10, \mathrm{Fe} 40, \mathrm{Mn} 60, \mathrm{Zn} 32.5$, I $0 \cdot 8$, Se $0 \cdot 1$, methionine 2200 , virginiamycine 20 .

the fats used in Expt 2 are given in Table 2. Body-weight gain and feed intake were measured throughout the experiments. The broilers were inoculated per os with 600000 sporulated Eimeria acervulina oocysts at $18 \mathrm{~d}$ of age. Oocysts were furnished by the Poultry Health Institute (Doorn, The Netherlands).

\section{Experimental design}

In Expt 1 each of the three treatments was made up of two replicates with ten chickens per replicate. While one treatment was not infected, two treatments were infected with Eimeria acervulina. All treatments received a control diet except for one infected treatment that 
Table 2. Fatty acid pattern $(\mathrm{g} / 100 \mathrm{~g}$ total fatty acids) of the fats used in Expt 2

\begin{tabular}{lccc}
\hline Fatty acid* & Animal fat & Coconut oil & Soyabean oil \\
\hline $8: 0$ & $\mathrm{Tr}$ & $7 \cdot 6$ & $\mathrm{Tr}$ \\
$10: 0$ & $\mathrm{Tr}$ & $\mathbf{6 \cdot 0}$ & $\mathrm{Tr}$ \\
$12: 0$ & $\mathrm{Tr}$ & $47 \cdot 1$ & $\mathrm{Tr}$ \\
$14: 0$ & $2 \cdot 1$ & $18 \cdot 1$ & $\mathrm{Tr}$ \\
$16: 0$ & $24 \cdot 6$ & $9 \cdot 4$ & $11 \cdot 0$ \\
$16: 1$ & $2 \cdot 4$ & $\mathrm{Tr}$ & $\mathrm{Tr}$ \\
$17: 0$ & $0 \cdot 7$ & $\mathrm{Tr}$ & $\mathrm{Tr}$ \\
$18: 0$ & $16 \cdot 2$ & $2 \cdot 8$ & 3.8 \\
$18: 1$ & $41 \cdot 8$ & $7 \cdot 0$ & $22 \cdot 7$ \\
$18: 2$ & $8 \cdot 5$ & $1 \cdot 9$ & $55 \cdot 6$ \\
$18: 3$ & $1 \cdot 1$ & $\mathrm{Tr}$ & $6 \cdot 6$ \\
$20: 1$ & $0 \cdot 7$ & $\mathrm{Tr}$ & $\mathrm{Tr}$ \\
\hline
\end{tabular}

Tr, trace $(<0.5 \mathrm{~g} / 100 \mathrm{~g})$.

* Traces of other fatty acids were present.

received the control diet with $0.4 \mathrm{~g}$ cholic acid/ $\mathrm{kg}$. Excreta were collected on days 16,21 and 24 in order to measure fat concentrations. On day 25, birds were killed to obtain ileum contents in order to measure $\mathrm{N}$ and starch concentrations. In addition livers were collected.

The four treatments in Expt 2 were made up of two replicates each, with twelve birds per replicate. While one treatment was not infected, three treatments were infected with Eimeria acervulina. The control treatment and one of the infected treatments received a diet containing animal fat. The other infected treatments were given a diet containing coconut oil or a diet containing soyabean oil. Excreta were collected on days 16 and 23 in order to measure fat concentrations.

\section{Analytical procedures}

Collection of livers and contents of intestines. Birds were killed and the contents of the ileum (the intestinal part from the yolk sac diverticulum to the ileocaecal junction) were collected. All samples, including liver samples from Expt 1, were pooled per experimental unit and stored at $-20^{\circ}$ until further analysis.

Vitamin A. Vitamin A (all trans-retinol), total carotenoids and $\beta$-carotene were determined in feed samples according to the methods of Fragner (1965) and Speek et al. (1986). In addition, vitamin A was determined in liver samples.

Fat, nitrogen and acid-insoluble ash. Fat, $\mathrm{N}$ and acid-insoluble ash concentrations were measured as described previously (Adams et al. 1996).

Starch. Starch was hydrolysed by amyloglucosidase (EC 3.2.1.3) and glucose was determined using the Luff-Schoorl reagent.

\section{Calculations}

Fat, protein and starch digestion were calculated according to the formulas used by Adams et al. (1996). Fat digestion was determined in excreta while protein and starch digestion were determined in ileal samples.

\section{Statistical procedure}

Analysis was based on group means. Treatment effects were determined using a one-way ANOVA achieved through the application of multiple regression procedures (Snedecor \& Cochran, 1980). The level of significance was set at $5 \%$. 
Table 3. Expt 1. Effect of cholic acid on digestion, vitamin $A$ concentration of the liver and performance after an Eimeria acervulina infection on day 18 in broiler chickens*

(Mean values for twenty birds per treatment)

\begin{tabular}{|c|c|c|c|c|c|}
\hline & Day & Control & Infection & $\begin{array}{c}\text { Infection } \\
+ \\
\text { cholic acid }\end{array}$ & LSD \\
\hline $\begin{array}{l}\text { Fat digestion (\%) } \\
\text { Protein digestion }(\%)^{\dagger} \\
\text { Starch digestion }(\%)^{\dagger}\end{array}$ & $\begin{array}{l}16 \\
21 \\
24 \\
25 \\
25\end{array}$ & $\begin{array}{l}82 \\
86 \\
86 \\
78 \\
94\end{array}$ & $\begin{array}{l}81 \\
22 \\
42 \\
79 \\
88\end{array}$ & $\begin{array}{l}84 \\
43 \\
57 \\
71 \\
88\end{array}$ & $\begin{array}{c}7 \\
3 \\
21 \\
5 \\
4\end{array}$ \\
\hline $\begin{array}{l}\text { Relative liver weight (\%) } \\
\text { Vitamin A (IU/g liver) } \\
\text { Vitamin A storage efficiency (\%) }\end{array}$ & $\begin{array}{l}25 \\
25 \\
25\end{array}$ & $\begin{array}{c}2 \cdot 6 \\
187 \\
39\end{array}$ & $\begin{array}{c}3 \cdot 0 \\
121 \\
28\end{array}$ & $\begin{array}{c}2 \cdot 9 \\
160 \\
35\end{array}$ & $\begin{array}{c}0.2 \\
14 \\
5\end{array}$ \\
\hline $\begin{array}{l}\text { Body-weight gain }(\mathrm{g}) \\
\text { Feed intake }(\mathrm{g}) \\
\text { Feed conversion }\end{array}$ & $\begin{array}{l}17-25 \\
17-25 \\
17-25\end{array}$ & $\begin{array}{l}354 \\
623 \\
1 \cdot 76\end{array}$ & $\begin{array}{l}299 \\
596 \\
1.99\end{array}$ & $\begin{array}{l}281 \\
557 \\
1.98\end{array}$ & $\begin{array}{l}25 \\
54 \\
0 \cdot 13\end{array}$ \\
\hline
\end{tabular}

LSD, least significant difference, based on ANOVA for two residual df. IU, international units.

* For details of procedures, see pp. 875-877.

$\uparrow$ Protein and starch digestion were measured in ileal samples.

$\$$ Vitamin A storage efficiency $(\%)=$ (total vitamin $A$ in liver/total vitamin A equivalents consumed) $\times 100$.

\section{RESULTS}

Cholic acid did not substantially improve fat digestion on day 16 which was $2 \mathrm{~d}$ before infection (Table 3). On day 3 postinfection (PI), fat digestion was severely depressed in the treatment group without cholic acid. However, the group receiving cholic acid showed an improvement in fat digestion. On day 6 PI the same trend was seen although the improvement in fat digestion when cholic acid was added was not statistically significant. No cholic acid controls were included in the experiment from day 18.

Protein and starch digestion were measured in the contents of the ileum on day 7 PI (Table 3). The infection did not lower protein digestion at this time. Starch digestion, however, was reduced. In the group supplemented with cholic acid, protein digestion was decreased while there was no effect on starch digestion.

Liver weight as a proportion of body weight was significantly increased on day 7 PI (Table 3) but absolute liver weights were not significantly different (results not shown) as a consequence of the infection. Relative vitamin A levels and vitamin A storage efficiency were significantly reduced as a result of the infection. However, when cholic acid was added to the diet, vitamin A levels and vitamin A storage efficiency were significantly increased in comparison with the infected group without cholic acid.

In Expt 1 the infection resulted in reduced body-weight gain and increased feed conversion during the period from day 17 to day 25 (Table 3). However, cholic acid did not significantly improve performance. In Expt 2 the infection resulted in significantly reduced body-weight gain and feed intake and significantly increased feed conversion from day 18 to day 23 (Table 4). When the infected groups were compared, coconut oil resulted in significantly improved performance in comparison with both animal fat and soyabean oil. Feed conversion values have been corrected for differences in metabolic energy.

In Expt 2 fat digestion was measured on day 16, just before the infection, and on day 23. On day 16 fat digestion was slightly increased in the groups receiving coconut or soyabean oil (Table 4). At day 23 fat digestion was severely decreased in the infected groups. 
Table 4. Expt 2. Effect of coconut oil or soyabean oil on fat digestion and performance after an Eimeria acervulina infection on day 18 in broiler chickens*

(Mean values for twenty-four birds per treatment)

\begin{tabular}{|c|c|c|c|c|c|c|}
\hline & \multirow[b]{2}{*}{ Day } & \multirow{2}{*}{$\begin{array}{c}\text { Control } \\
\text { animal fat }\end{array}$} & \multicolumn{3}{|c|}{ Infection } & \multirow[b]{2}{*}{ LSD } \\
\hline & & & Animal fat & Coconut oil & Soyabean oil & \\
\hline $\begin{array}{l}\text { Body-weight gain (g) } \\
\text { Feed intake (g) } \\
\text { Feed conversion } \dagger\end{array}$ & $\begin{array}{l}18-23 \\
18-23 \\
18-23\end{array}$ & $\begin{array}{l}242 \\
424 \\
1 \cdot 75\end{array}$ & $\begin{array}{l}184 \\
378 \\
2 \cdot 05\end{array}$ & $\begin{array}{l}215 \\
393 \\
1 \cdot 85\end{array}$ & $\begin{array}{l}193 \\
382 \\
2 \cdot 04\end{array}$ & $\begin{array}{l}15 \\
14 \\
0 \cdot 11\end{array}$ \\
\hline $\begin{array}{l}\text { Fat digestion (\%) } \\
\text { Fat digestion (\%) }\end{array}$ & $\begin{array}{l}16 \\
23\end{array}$ & $\begin{array}{l}81 \\
87\end{array}$ & $\begin{array}{r}83 \\
8\end{array}$ & $\begin{array}{l}89 \\
49\end{array}$ & $\begin{array}{l}89 \\
16\end{array}$ & $\begin{array}{r}6 \\
27\end{array}$ \\
\hline
\end{tabular}

LSD, least significant difference, based on ANOVA for three residual df.

* For details of procedures, see pp. 875-877.

$\dagger$ Feed conversion is corrected for differences in metabolic energy.

However, the differences between the fats that were used were striking. Fat digestion of the infected group that was given coconut oil was improved in comparison with the infected group that was given animal fat. However, fat digestion of the infected group that was given soyabean oil did not improve significantly.

\section{DISCUSSION}

In chickens ingested lipids undergo intestinal emulsification, lipolysis, micellar solubilization, cell membrane permeation, intracellular esterification and incorporation into lipoproteins before release to the interstitial fluid. It is not certain which part of fat digestion is most severely affected during an infection with Eimeria acervulina. In Expt 1 it was investigated whether emulsification of fat is the rate-limiting step during infection. Bile salts are necessary for emulsification of lipids and micelle formation. It is indicated that fatty acid utilization varies with bile acid concentration in the intestine (Krogdah1, 1985). In young chickens fat digestion is not fully developed (Katangole \& March, 1980) and this may be a result of underdeveloped bile acid function (Green \& Kellogg, 1987). Polin et al. (1980) found that addition of $0.4 \mathrm{~g}$ cholic acid $/ \mathrm{kg}$ diet improved fat digestion from 76 to $81 \%$ in 1-week-old chickens.

In Expt 1 only a slight improvement of fat digestion was found when cholic acid was added to the diet of broilers aged $16 \mathrm{~d}$, but fat digestion was already high at this time. However, when birds were infected with Eimeria acervulina fat digestion was reduced from 86 to $22 \%$ and could be increased to $43 \%$ with the addition of cholic acid at $21 \mathrm{~d}$ of age. The same was seen with vitamin A concentration of the liver and vitamin A storage efficiency. Vitamin $A$ is fat soluble and absorption into the intestinal cell is similar to absorption of most other lipids. However, feed intake and body-weight gain were not improved by cholic acid as a result of high least significant difference values.

In Expt 2 we tried to improve fat digestion during the infection by replacing animal fat with vegetable fats. Animal fat has a relatively high content of saturated fatty acids and oleic acid (18:1). Coconut oil, however, has a high concentration of lauric acid (12:0) and myristic acid (14:0), while soyabean oil has a high content of both oleic acid and linoleic acid (18:2). As a result of differences in chain length and molecular form, medium-chain fatty acids and unsaturated fatty acids are better utilized than long-chain saturated fatty acids. 
Patients with intestinal disorders frequently use fats containing medium-chain fatty acids in order to improve fat digestion. MCT fats have certain advantages over LCT. First, water solubility of MCT is greater, so bile salts are not required for dispersion in water. In addition, MCT may enter enterocytes without hydrolysis as a result of their smaller molecular size. Furthermore, MCT present a greater surface for lipase enzyme action, so hydrolysis is more rapid. Lastly, the shorter chain length of the fatty acids results in more efficient absorption by the diseased mucosal surface (Babayan, 1987).

Coconut oil significantly improved fat digestion and performance values during the infection. Together with the characteristics of MCT fats mentioned previously it might be concluded that coccidiosis leads to reduced bile salt secretion, reduced lipase activity or mucosal damage. However, the results of Expt 1 indicate that reduced bile salt secretion is probably the most important factor affecting fat digestion during infection.

In general unsaturated fatty acids are better utilized than saturated fatty acids because they are more polar than saturated fatty acids. This results in improved micelle formation (Garrett \& Young, 1975). However, during the coccidiosis infection of Expt 2 a high concentration of unsaturated fatty acids (soyabean oil) did not improve fat digestion.

The infection with Eimeria acervulina was used as a model to test different diet compositions in order to improve nutrient utilization during coccidiosis. Fat digestion could be ameliorated by adding cholic acid or by using coconut oil instead of animal fat. As the model seems to be valuable to test effects on fat digestion during infection, it is possible that improved protein retention might be found when using a suitable diet.

The authors wish to thank H. W. Peek and M. H. Vertommen of the Poultry Health Institute, Doorn, The Netherlands for kindly providing Eimeria acervulina oocysts. This study was financially supported by the Dutch Department of Economics.

\section{REFERENCES}

Adams, C., Vahl, H. A. \& Veldman, A. (1996). Interaction between nutrition and Eimeria acervulina infection in broiler chickens: development of an experimental infection model. British Journal of Nutrition 75, 867-873.

Babayan, V. K. (1987). Medium-chain triglycerides and structured lipids. Lipids 22, 417-420.

Bach, A. C. \& Babayan, V. K. (1982). Medium-chain triglycerides: an update. American Journal of Clinical Nutrition 36, 950-962.

Fragner, J. (1965). Vitamine und Biochemie, Band I, p. 273. Jena: Gustav Fisher Verlag.

Garrett, R. L. \& Young, R. J. (1975). Effect of micelle formation on the absorption of neutral fat and fatty acids by the chicken. Journal of Nutrition 105, 827-838.

Green, J. \& Kellogg, T. F. (1987). Bile acid concentrations in serum, bile, jejunal contents and excreta of male broiler chicks during the first six weeks posthatch. Poultry Science 66, 535-540.

Katangole, J. B. D. \& March, B. E. (1980). Fat utilization in relation to intestinal fatty acid binding protein and bile salts in chicks of different ages and different genetic sources. Poultry Science 59, 819-827.

Krogdah1, A. (1985). Digestion and absorption of lipids in poultry. Journal of Nutrition 115, 675-685.

National Research Council (1984). Nutrient Requirements of Poultry, 8th ed. Washington: National Academy Press.

Polin, D., Wing, T. L., Ki, P. \& Pell, K. E. (1980). The effect of bile acids and lipase on absorption of tallow in young chicks. Poultry Science 59, 2738-2743.

Snedecor, G. W. \& Cochran, W. G. (1980). Statistical Methods, 7th ed. Iowa: Iowa State University Press.

Speek, A. J., Demalilwa, C. R. \& Schrijver, J. (1986). Determination of $\beta$-carotene content and vitamin A activity of vegetables by HPLC and spectrophotometry. Food Chemistry 19, 359-361. 